\title{
Complete Optimizer for Dispatching Schedule of Ready Mix Concrete Plant
}

\author{
Mr. A. K. Gaikwad ${ }^{1}$ \\ ${ }^{1}$ Research Scholar, \\ Civil Engineering Department \\ D Y P IoT, Pimpri, Pune
}

\author{
Dr. S. B.Thakare ${ }^{2}$ \\ ${ }^{2}$ Research Guide, Professor, \\ Civil Engineering Department \\ D Y P IoT, Pimpri, Pune
}

\begin{abstract}
Dispatching Ready Mixed Concrete (RMC) to construction sites is an important task of the RMC batch plant manager. The RMC batch plant manager has to prepare an efficient schedule of dispatching RMC trucks, which will optimizes the waiting time of RMC trucks at the construction sites and also at the batch plant. The existing dispatching schedule mainly depends on the experiences of the dispatching manager and preferences from site. See if, the RMC plant manager dispatches more and more RMC trucks to the required construction site, it results in the lineup of RMC trucks at one site and keeping other sites waiting for the arrivals of RMC trucks, called as 'interruption'. Also when the RMC trucks are dispatched as per the industry logic, more number of trucks are required than optimized value. In this paper attempt is made to reduce the interruption time by applying evolutionary Genetic Algorithm (GA) optimization techniques and also to reduce number of trucks to optimum value. A user-friendly computer program is developed in MATLAB environment to help the plant manager to decide un-interrupted dispatching schedule.
\end{abstract}

Key words: GA's applications, Un-interrupted Dispatching, dispatching time of RMC trucks, Optimization of Dispatching schedule, Reduction of waiting time for dispatching RMC, Optimization of RMC trucks.

\section{INTRODUCTION:}

Ready Mix Concrete (RMC) is one of the most popular building materials in construction industry. RMC is prepared generally in a concrete batch plant where ingredients are weighed and mixed by automated devices as per the demands of the construction sites. RMC is commonly used for all types of constructions due to its several benefits like uniformity and faster production, compared to concrete prepared by conventional methods. RMC usually needs to be poured within approximately 1 1.5 Hrs, after being produced by the RMC batch plant, which limits the service area of delivery. Consequently, RMC industry is concern about production and scheduling of truck dispatching. Dispatching scheduling can be done manually by experienced staffs, but it may leads to the possibility of interruptions at construction site. In the present study GA model has been developed to reduce the interruption of construction sites. The GA is a global stochastic search technique based on the Darwinian Survival-of-the-fittest principle (Holland1975). A brief review of GA application to RMC trucks dispatching was found in Feng (2004). Chung et. al. (2004) has developed simulation and GA optimization to reduce waiting time of RMC trucks at construction site. Naso (2005) have applied
GA model for optimal delivery of RMC on site. Fritz Payr and Verena Schmid (2009) developed a mathematical model for RMC delivery problem and provided a solution with VNS technique. Nuntana and Wuthichai (2015) suggested an approach giving better than GA, but the interruptions are not reduced to zero and comparison of the results with industry is missing, moreover flexibility to the batch plant manager was not given to make changes in the algorithm. The overall goal was to deliver RMC to various sites on time and as cost-effective as possible. The main objective of this study is to develop user-friendly model in MATLAB environment to decide un-interrupted dispatching schedule of RMC trucks and also to reduce number of trucks required to dispatch the RMC demands compared to present industry logic.

\section{FACTORS AFFECTING THE DISPATCHING SCHEDULE OF RMC TRUCKS:}

Important factors affecting the dispatching of RMC schedule of trucks in India are as shown in Fig.1:

The peripheral are the factors pertaining to batch plant, whereas, those inside the circle are pertaining to the construction site location from batch plant.

\subsection{Start Time of Casting (STC):}

Generally in India the casting is started in the morning from $7 \mathrm{am}$ to $11 \mathrm{am}$. But in some extreme conditions it can be up to $4 \mathrm{pm}$.

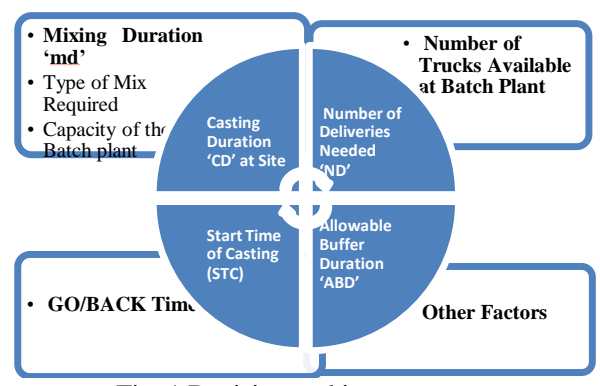

Fig. 1 Decision making parameters

\subsection{Traveling duration from plant to the job site $(G O \&$ $B A C K)$ :}

The traveling duration between the RMC batch plant and the job site is depending on the distance between site and plant, the speed of the RMC truck and the traffic condition. Therefore, it is not easy to predict the exact duration required to deliver RMC to different construction sites. The 
batch plant manager, as a thumb rule, usually assigns the RMC trucks to the job site far from the batch plant with higher priority to avoid discontinuity of casting. However, such an approach increases the chances of interrupting the working process at other job sites, which has faster casting time. Therefore, the traveling duration between the RMC plant and the job site becomes a major factor in deciding the schedule of dispatching RMC trucks. In practice, the average traveling duration between the batch plant and the construction site can be estimated from the history data or by considering average speed of the RMC truck.

\subsection{The operating/casting duration (CD) of RMC at the job site:}

The duration of casting RMC at the job site depends on the types of the construction activities as well as the height of delivery(Dumping or Pumping), which may affect the dispatching interval between assigning RMC trucks to the same job site. For example, the faster the casting duration, shorter is the dispatching interval between them. If the RMC trucks cannot arrive at the job site in time, it leads to the interruption of the construction activity.

\subsection{Number of deliveries/trucks (i.e. Volume of RMC) needed (ND):}

Number of RMC trucks, are dependent on the amount of $\mathrm{RMC}$ required at construction site, loading capacity of the truck, and the traffic on road. See, higher the capacity of trucks lesser the number of deliveries needed. And lesser the number of deliveries needed lesser the casting time of that site.

\subsection{Number of trucks available at Batch Plant $(C)$ :}

If the waiting time at a site increases, number of trucks required at a batch plant increase, which may leads to the extra investment of the RMC batch plant. This computer program generated in MATLAB environment, gives the optimum number of the trucks required for a batch plant.

\subsection{Other Constraints:}

The RMC is to be casted between 1-1.5 Hrs of its loading, so a Allowable Buffer Time (ABT) is also to be provided for every site and every delivery, which is the balance time duration after considering all the above mentioned durations like GO, BACK and CD.

Besides all these parameters, there are some critical parameters, which cannot be considered, if dispatching schedule is to be prepared manually.

\section{LIMITATIONS OF THE PRESENT WORK AND} INDUSTRY:

- Present work is focused on number of trucks required based delivery of concrete and not volume based schedule, which gives better, (> $60 \%$ saving in waiting time), results than the present work.

- Present work is for single plant multi sites conditions, scope for more research on multi plants and multi sites conditions.

\section{APPLICATION OF THE PROGRAM FOR PREPARING AN UN-INTERRUPTED DISPATCHING SCHEDULE OF RMC TRUCKS:}

There are various types of batch plants according to Capacity of Plant (CP) to manufacture an amount of cubic meters of concrete in one hour e.g. CP-30, CP-60 and CP90 i.e. 30,60 and $90 \mathrm{~m}^{3}$ per hour of concrete get produced by the plant.

Generally CP-30 requires 20 minutes to fill one truck of 6 $\mathrm{m}^{3}$ (approximately) where as CP-60 and CP-90 requires 8 minutes and 3 minutes respectively.

\section{EXAMPLE 1 (For CP-90):}

Table 1 Consider a site situation with following data:

\begin{tabular}{|c|c|c|c|c|c|c|}
\hline $\begin{array}{c}\text { Site } \\
\text { ID }\end{array}$ & STC & GO & CD & BACK & ABD & ND \\
\hline Site 1 & $8: 00 \mathrm{am}$ & 30 & 20 & 25 & 30 & 3 \\
\hline Site 2 & $8: 00 \mathrm{am}$ & 25 & 30 & 20 & 20 & 4 \\
\hline Site 3 & $8: 30 \mathrm{am}$ & 40 & 25 & 30 & 15 & 5 \\
\hline \multicolumn{7}{|c|}{ Number of Trucks at Batch Plant : } \\
\hline \multicolumn{3}{|c|}{ Mixing Duration of Plant } & : & \multicolumn{3}{|c|}{3 minute $(\mathbf{m d})$} \\
\hline \multicolumn{3}{|c|}{ Max. Capacity of the Truck } & : & \multicolumn{3}{|c|}{$6 \mathrm{M}^{3}$} \\
\hline
\end{tabular}

Where,

STC : Start casting time of the construction site (in $24 \mathrm{~h}$ format).

CD : Casting duration of the construction site (in min).

GO : Traveling duration from the batch plant to the construction site (in $\mathrm{min}$ ).

BACK : Traveling duration from the construction site to the batch plant (in min)

ABD : The allowable buffer duration of construction site (in min).

ND : The number of RMC truck deliveries required for the construction site.

mo : The mixing duration in min

C : The number of trucks available at Batch Plant.

Step 1: Fill all the above data in the "DiScO for RMC" App made in MATLAB and determine the ideal departing time of each RMC truck. The ideal departing time of each RMC truck, shown in Table 2, is determined by using Equations (1) and (2).

Table 2 Earliest departing times of RMC trucks:

FDT $\min [08: 00-00: 30,08: 00-00: 25,08: 30-00: 40]=07: 30$

\begin{tabular}{lllllllllllll}
\hline I & 1 & 2 & 3 & 4 & 5 & 6 & 7 & 8 & 9 & 10 & 11 & 12
\end{tabular}

$\begin{array}{lllllllllllll}\text { IDT } & 07: 30 & 07: 33 & 07: 36 & 07: 39 & 07: 42 & 07: 45 & 07: 48 & 07: 51 & 07: 54 & 07: 57 & 08: 00 & 08: 03\end{array}$

$$
\begin{aligned}
& \mathrm{FDT}=\min (\mathrm{STC}-\mathrm{GO})_{\mathrm{i}, \mathrm{i}} \mathrm{i}=1 \text { to } \mathrm{m} \\
& \mathrm{IDT}_{\mathrm{i}}=\mathrm{FDT}+(\mathrm{i}-1)^{*} \mathrm{md}, \mathrm{i}=1 \text { to } \mathrm{N}
\end{aligned}
$$

Where

$$
\mathrm{n}=\sum_{i=1}^{m} \mathrm{ki}
$$

FDT is the departing time of the first dispatched truck,

IDT is the ideal departing time of the dispatched truck,

i is the dispatched order of the truck,

m is the number of construction sites that request RMC deliveries,

$\mathbf{k}$ is the required RMC deliveries of the construction site,

n is the total number of the RMC deliveries for all construction sites. 
Step 2: The ideal departing time of each RMC truck can be determined by step 1 . However, the capacity of the batch plant is limited to five trucks, it is possible that the batch plant cannot delivery RMC because, yet none of these trucks have come back. Therefore, only the departing time of the first five dispatched RMC trucks from the batch plant is determined and the departing time for the rest of trucks is decided by knowing back time of any of these trucks, according to the dispatching sequence generated by the GA. Table 3 shows an example of the dispatching sequence generated by the GA. The calculations starts with the first dispatched RMC truck which departs from the batch plant at 07:30 Hrs. Table 4 records the process of the simulation according to Eqs. (3)-(11) and (Table 4) also shows the simulated result according to the dispatching sequence and simulation process.

IF $\mathrm{i}<=\mathrm{n}$, Number of Trucks at Batch Plant,

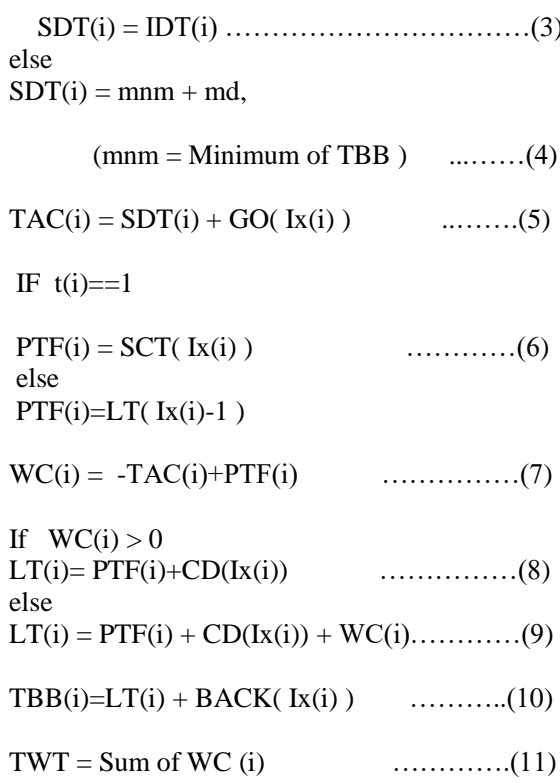

Table 3 Dispatching sequence generated by GA for $1^{\text {st }}$ Generation:

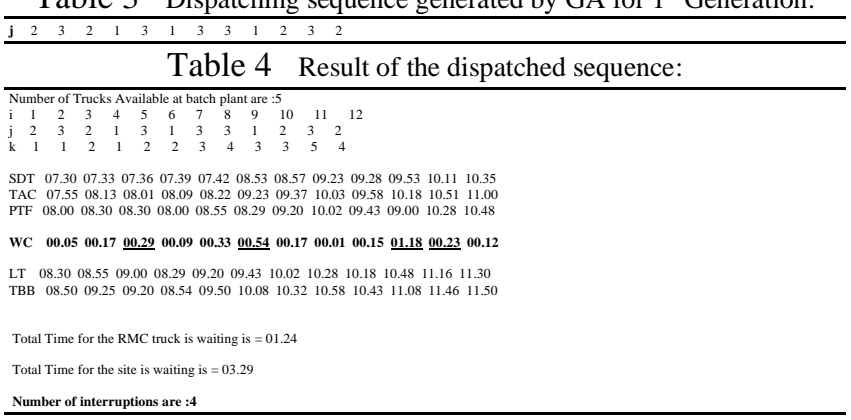

Where,

SDT is the simulated departing time of dispatched truck,

TAC is the time that dispatched truck arrives at construction site,

PTF is the start casting time of the construction site,

WC is the duration that dispatched truck waits at the construction

site,

-WC is the duration that construction site waits for the arrival of the

truck,

LT

TBB

i

j

is the time that the RMC truck leaves construction site,

is the time that the RMC truck back to the batch plant,

is the dispatching order of the RMC trucks,

is the dispatched sequence to the site number, construction site,

Step 3: Determine the fitness value using Eq. (12) and (13). From the Table 5, the total duration that RMC trucks wait at construction sites and total duration that construction sites wait for the arrival of RMC trucks are 84 and $209 \mathrm{~min}$, respectively. The interruption of casting concrete occurs when the duration that the construction site waits for the arrival of the RMC truck is longer than the allowable buffer duration. As shown in Table 5, the number of interruptions marked with under lines, are 4. Since the interruptions of casting concrete should be avoided as far as possible, the penalty value is calculated by Eq. (12).

$\mathrm{P}=$ (Number of interruption) $\times 60 \times 24$

The Fitness Value (FV) of a dispatched schedule is defined as $\mathrm{FV}=\mathrm{P}+\mathrm{TWC}$, where TWC is the total duration that RMC trucks wait at the construction sites. In this example, the fitness value of the dispatched schedule is equal to 5844 ( = $4 \times 60 \times 24+84)$, where ' 4 ' is number of interruptions.

$\mathrm{FV}=\mathrm{P}+84$

And then obtain a final dispatching order (as shown in Table 5) of RMC trucks by using the GA tool in MATLAB. At the same time it will generate the graph of "Fitness value X Number of Generations". For which we have to select the number of generations, limits of the variables and number of variable (total number of trucks to be delivered).

Step 4: This dispatching order (as shown in the Table 5) is get copied in the "Result" program in coded in MATLAB. Run this program, which will generate the results in the "Output" file, as shown in the Table 6 (also in the tab 'View Results').

Table 5 Final Dispatching sequence generated by GA:

Table 6 Results of dispatched sequence generated by MATLAB Program :

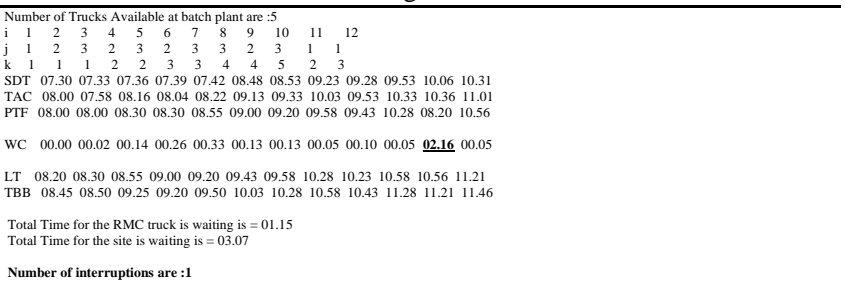

Step 5: The Table 6 gives the scope to shift the casting time of any of the sites (e.g. Site $2 \& 3$ in our case), so as to reduce the number of interruption, shown by underline as 1. Now if the casting time of Site $2 \& 3$ is made as per Table 7 the number of interruptions can be reduced to zero refer final output in Table 10. Also Refer the out-puts generated as per the RMC Dispatching Managers logic from a Batch Plant in Pune, Maharastra, India, as shown in the Table 8 \& Table 9. 
Table 7 Optimum Solution can be decided by changing the times from the results generated:

Changes are made in the Table 1 for Start Casting Time:

\begin{tabular}{|c|c|c|c|c|c|c|}
\hline $\begin{array}{c}\text { Site } \\
\text { ID/m }\end{array}$ & STC & GO & CD & BACK & $\overline{\text { ABD }}$ & $\mathrm{ND} / \mathrm{k}$ \\
\hline Site 1 & $8: 00 \mathrm{am}$ & 30 & 20 & 25 & 30 & 3 \\
\hline Site 2 & $8: 15 \mathrm{am}$ & 25 & 30 & 20 & 20 & 4 \\
\hline Site 3 & $9: 45 \mathrm{am}$ & 40 & 25 & 30 & 15 & 5 \\
\hline \multicolumn{3}{|c|}{ Mixing Duration at Plant } & $\begin{array}{l}: \\
:\end{array}$ & & $\begin{array}{l}\text { S (c) } \\
\text { (md) }\end{array}$ & \\
\hline
\end{tabular}

Table 8 Results as per Batch Plant managers logic without changes in Casting Time:

\begin{tabular}{lllllllllllll}
\hline Number of Trucks Available at batch plant are :5 & 10 & 11 & 12
\end{tabular}

$\begin{array}{lllllllllllll}\mathrm{i} & 1 & 2 & 3 & 4 & 5 & 6 & 7 & 8 & 9 & 10 & 11 & \\ \mathrm{j} & 1 & 1 & 1 & 2 & 2 & 2 & 3 & 3 & 3 & 2 & 3 & 3\end{array}$

$\begin{array}{lllllllllllll}\mathrm{k} & 1 & 2 & 3 & 1 & 2 & 3 & 1 & 2 & 3 & 4 & 4\end{array}$

$\begin{array}{llllllllllllll}\text { SDT } & 07.30 & 07.33 & 07.36 & 07.39 & 07.42 & 08.48 & 08.57 & 09.08 & 09.27 & 09.28 & 10.06 & 10.35\end{array}$

$\begin{array}{llllllllllllll}\text { TAC } & 08.00 & 08.03 & 08.06 & 08.04 & 08.07 & 09.13 & 09.37 & 09.48 & 10.07 & 09.53 & 10.46 & 11.15\end{array}$

$\begin{array}{lllllllllllllll}\text { PTF } & 08.00 & 08.20 & 08.40 & 08.00 & 08.34 & 09.04 & 08.30 & 10.02 & 10.27 & 09.43 & 10.52 & 11.17\end{array}$

$\begin{array}{llllllllllllllllll}\text { WC } & 00.00 & 00.17 & 00.34 & 00.04 & 00.27 & 00.09 & 01.07 & 00.14 & 00.20 & 00.10 & 00.06 & 00.02\end{array}$

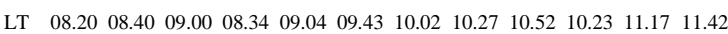
$\begin{array}{lllllllllllllll}\text { TBB } & 08.45 & 09.05 & 09.25 & 08.54 & 09.24 & 10.03 & 10.32 & 10.57 & 11.22 & 10.43 & 11.47 & 12.12\end{array}$

Total Time for the RMC truck is waiting is $=02.00$

Total Time for the site is waiting is $=01.30$

Total Time of waiting is $=\mathbf{0 3 . 3 0}$

Number of interruptions are : 1

Table 9 Results as per Batch Plant Managers logic with changes in Casting Time:

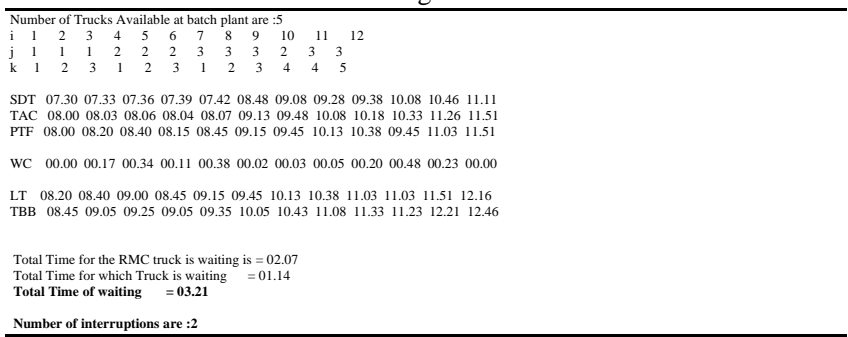

Table 10 Final Results generated by MATLAB Program with changes in Casting Time:

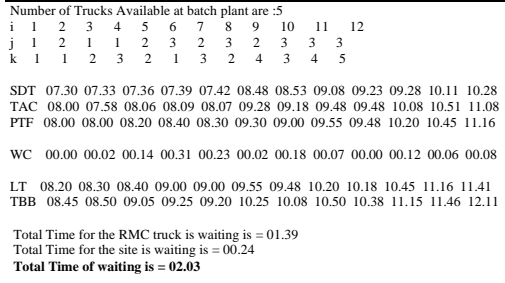

Number of inter

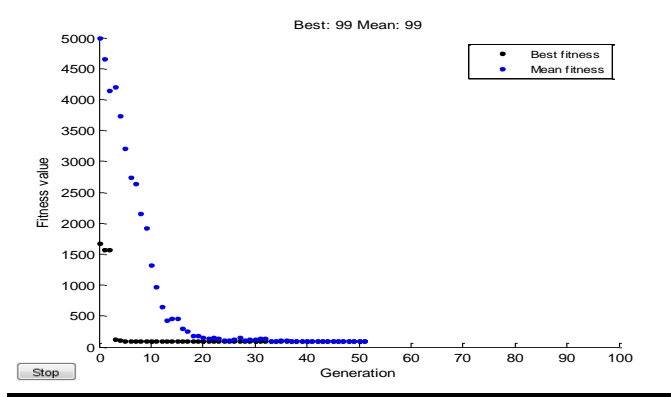

Fig. 2: Result of Example 1

The graph in Fig. 2, shows the relation of 'Fitness' and 'Generation', i.e. the fitness values (Best value of that iteration) at every iteration that the program works and gives the FV value for that iteration called as 'Generation'. And moreover after $20^{\text {th }}$ iterations the best value goes on remaining same to that of mean value, and so finally about $52^{\text {nd }}$ generation the final (Fittest FV) is displayed as final dispatching sequence. The 'Best Values' remaining same from $20^{\text {th }}$ to $52^{\text {nd }}$ iterations are all the possibilities, that the dispatching sequence will generate same waiting time, and so it will be displayed as the final value.

EXAMPLE 2 (For CP-30):

Table 11 Consider a site situation with following data:

\begin{tabular}{l}
\begin{tabular}{|c|c|c|c|c|c|c|}
\hline Site ID & STC & GO & CD & BACK & ABD & ND/k \\
\hline Site 1 & $8: 00$ am & 30 & 20 & 25 & 30 & 3 \\
\hline Site 2 & $8: 00 \mathrm{am}$ & 25 & 30 & 20 & 20 & 4 \\
\hline Site 3 & $8: 30$ am & 40 & 25 & 30 & 15 & 5 \\
\hline Number of Truck at Batch Plant & $\vdots$ & 05 Trucks (c) \\
Mixing Duration at Plant \\
Max. Capacity of the Truck
\end{tabular} \\
\hline
\end{tabular}

Table 12 Final dispatching order generated by GA:

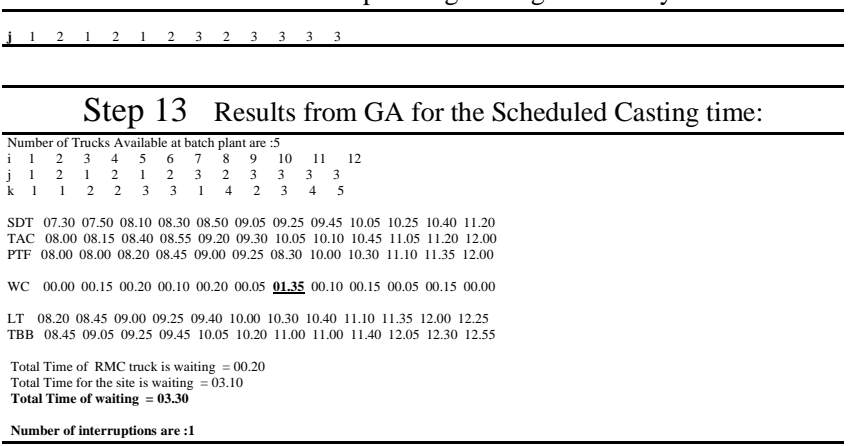

Table 14 Corrections/alteration made in Casting time for site $2 \& 3$ :

\begin{tabular}{|c|c|c|c|c|c|c|}
\hline $\begin{array}{c}\text { Site } \\
\text { ID/m }\end{array}$ & STC & GO & CD & BACK & ABD & ND/k \\
\hline Site 1 & $8: 00 \mathrm{am}$ & 30 & 20 & 25 & 30 & 3 \\
\hline Site 2 & $9.00 \mathrm{am}$ & 25 & 30 & 20 & 20 & 4 \\
\hline Site 3 & $10.00 \mathrm{am}$ & 40 & 25 & 30 & 15 & 5 \\
\hline
\end{tabular}

Table 15 Results by Managers logic without changes in the Casting time:

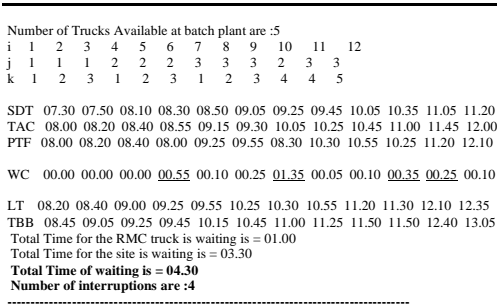

Table 16 Results by Managers logic with changes in Casting time:

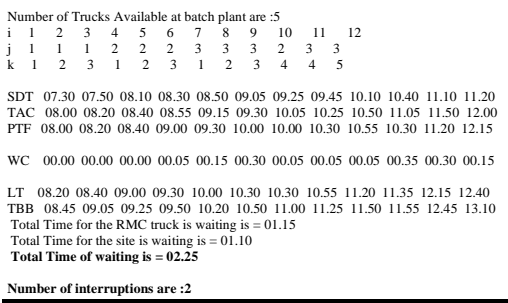

Number of interruptions are $: 2$ 
Table 17 Final Results generated by MATLAB after the changes in Casting Time:

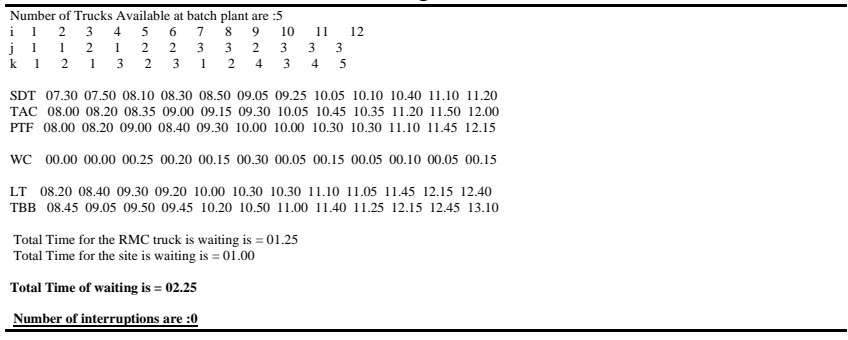

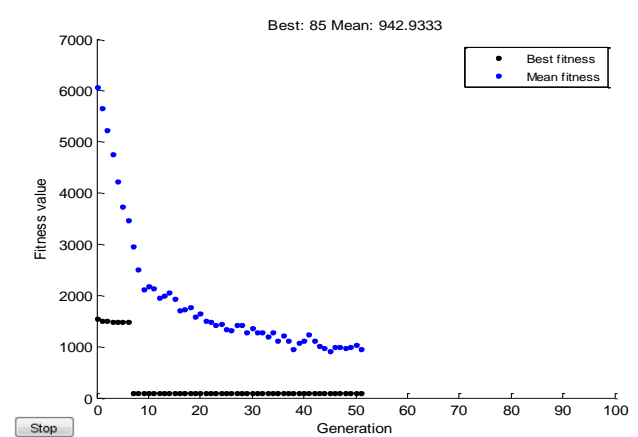

Fig. 3: Result of Example 2

The graph in Fig. 3, shows the relation of 'Fitness' and 'Generation', i.e. the fitness values (Best value of that iteration) at every iteration that the program works and gives the FV value for that iteration called as 'Generation'. And moreover after $8^{\text {th }}$ iterations the fitness values goes on remaining same to the mean value, and so finally about $52^{\text {nd }}$ generation the final (Fittest FV) is displayed as final dispatching sequence. The 'Best Values' remaining same from $8^{\text {th }}$ to $52^{\text {nd }}$ iterations are all the possibilities, that the dispatching sequence will generate same waiting time, and so it will be displayed as the final value.

These two sample examples are the demonstration of the, the program and its logic compared with the industry logic. Various critical cases have been identified from literature review and with industry discussion, for testing the efficiency and effectiveness of the model. Four cases of CP-30 plant have been identified and same were tested for CP-90 plant also and results are compared for their percentage savings in TWT.

After comparing such 8 different critical cases results are summarized in tabular and graphical form as follows,

Table 18 Summary of the Results

\begin{tabular}{|c|c|c|c|c|c|c|c|}
\hline \multirow[t]{2}{*}{$\begin{array}{l}\text { Case } \\
\text { No. }\end{array}$} & \multirow[t]{2}{*}{$\begin{array}{l}\begin{array}{l}\text { No. of } \\
\text { Sites }\end{array} \\
\end{array}$} & \multirow[t]{2}{*}{$\begin{array}{c}\text { Mixing } \\
\text { Duration }\end{array}$} & \multirow{2}{*}{$\begin{array}{c}\text { No. of Trucks } \\
\text { To be } \\
\text { Dispatched }\end{array}$} & \multicolumn{2}{|c|}{$\begin{array}{l}\text { TWT/No. of interruptions } \\
(\mathrm{Hrs}: \min / \mathrm{No} \text {.) As per }\end{array}$} & \multirow{2}{*}{$\begin{array}{c}\text { Total } \\
\text { Saving } \\
\text { in TWT } \\
\text { (Hrs: } \\
\text { min) }\end{array}$} & \multirow{2}{*}{$\begin{array}{c}\% \% \\
\begin{array}{c}\% \text { Saving } \\
\text { in TWT }\end{array}\end{array}$} \\
\hline & & & & $\begin{array}{c}\text { Industry } \\
\text { Logic }\end{array}$ & $\begin{array}{c}\text { GA } \\
\text { Model }\end{array}$ & & \\
\hline 2 & 3 & \multirow{4}{*}{$\begin{array}{c}\begin{array}{c}20 \\
\text { minutes }\end{array} \\
\text { CP-30 }\end{array}$} & 12 & $2: 15 / 2$ & $1: 10 / 0$ & $1: 05$ & 49.00 \\
\hline 4 & 2 & & 18 & $4: 40 / 4$ & $3: 55 / 1$ & $0: 45$ & 16.07 \\
\hline 6 & 5 & & 18 & $6: 40 / 1$ & $5: 45 / 0$ & $0: 55$ & 13.75 \\
\hline 8 & 2 & & 12 & $2: 40 / 2$ & $2: 30 / 0$ & $0: 10$ & 6.25 \\
\hline 1 & 3 & & 12 & $3: 30 / 1$ & $2: 03 / 0$ & $1: 27$ & 60.47 \\
\hline
\end{tabular}

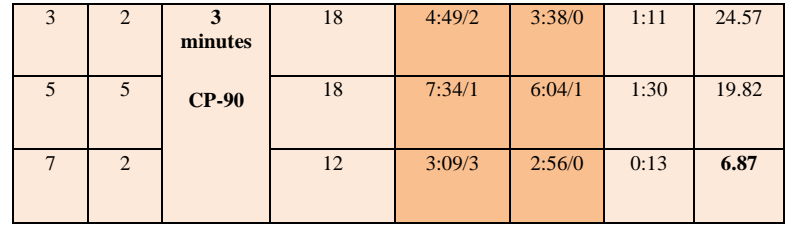

Saving in Total Waiting Time CP-30

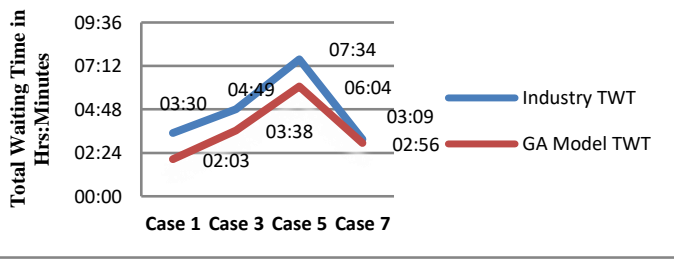

Fig. 4 Saving in TWT for CP-30

Saving in Total Waiting Time CP-90

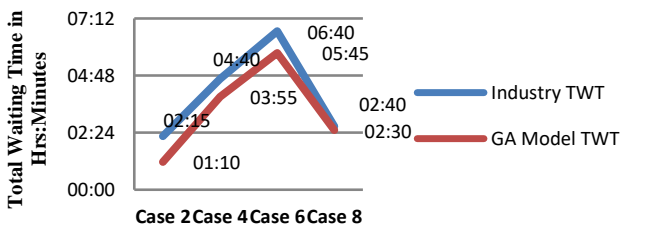

Fig. 5 Saving in TWT for CP-90

From Fig. 4 and Fig. 5 we can conclude, that the Total Waiting Time (TWT) required in suggested GA model is always less than the Industry Logic and as per the Table 18 , it is less by $6 \%$ to $60 \%$.

\section{6. 'DISCO FOR RMC' APP:}

The main objective of this study is to develop userfriendly App / model in MATLAB environment by linking two different programs codes: one for optimization of TWT and one for display of the results. The prepared App, named "DiScO for RMC Trucks", has a user interface as shown Fig. 6.

After filling the data for decision making parameters as discussed in Example 1and shown in the user interface, press "RUN" button, the results will be displayed on the same screen as shown in Fig. 7.

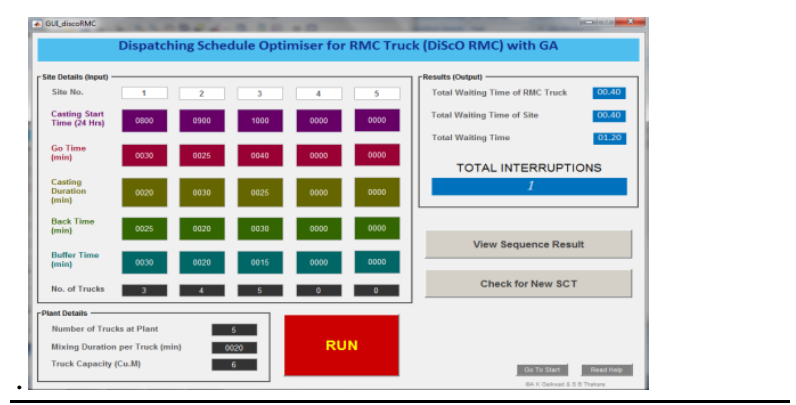

Fig. 6 User interface of the App for GA model

Now click on the "View Sequence Result", to see, the sequence to be dispatched against the column shown by ' $\mathrm{j}$ '. 


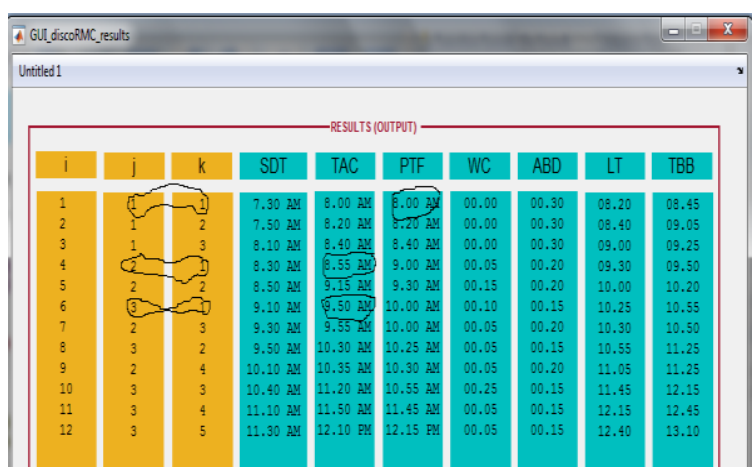

Fig. 7 Screen display for "View Sequence Result" operation

Now press on, "Check for New SCT", and make changes (in SCT for non ZERO interruptions) as shown in Fig. 8, by click on "Calculate for New SCT",

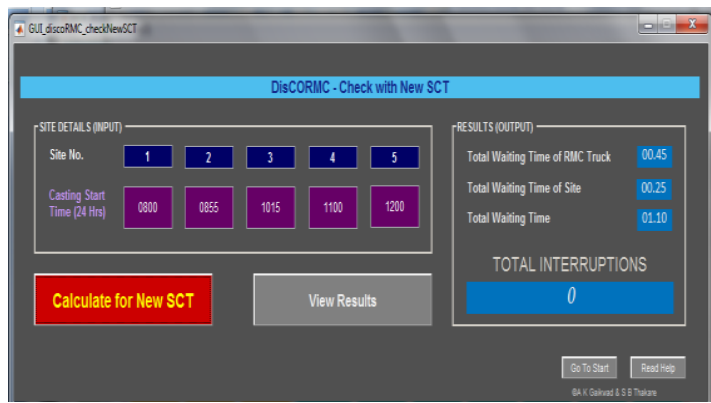

Fig. 8 Screen display for "Check for New SCT".

This is to be done till the "interruptions" are reduced to ZERO. Whereas the results by Batch Plant Managers logic can be checked with, the model result by another single window interface as shown in Fig. 9. This is opened by clicking "Go To Start", and then click on "YES". Make entry of data (especially for Dispatching sequence) for decision making parameters and click on "RUN", it show the result as per industry logic, shown below,

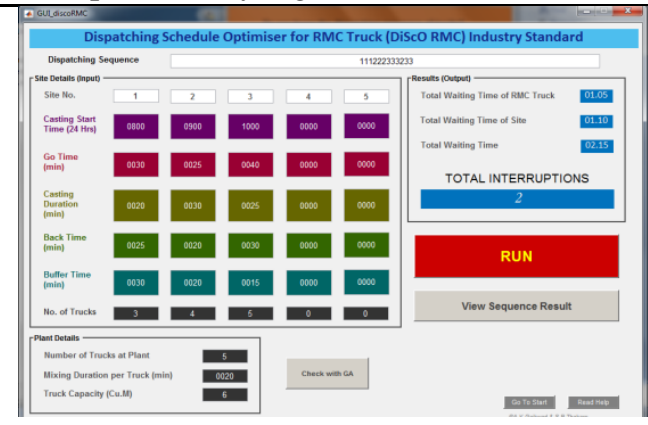

Fig. 9 User interface of the App for Industry logic

The results for all the 8 different cases displayed in Table 18.

\section{CHANGES AND APPLICATION OF MODEL FOR TRUCK OPTIMIZATION:}

As discussed earlier, industry is using thumb rule as its own logic for the dispatching, which leads in more
TWT and interruptions. It is also observed that the industry uses more number of trucks than what they are actually required to have uninterrupted dispatching. Following is the stepwise procedure for optimization of number of trucks.

Step 1: Fill all the data for decision making parameters, in the model and determine the Total waiting time (TWT) for the given dispatching sequence according to the industry logic using "RUN" tab shown in Fig. 9. Thumb rule for CP-30 is: three trucks per site in sequence by balancing earlier remaining demand of site i.e. If 3,4 and 5 trucks are required for 3 sites named 1,2 and 3 as shown in Example 1 above, the sequence to be dispatched will be 111 (three trucks of 'Site 1') 222 (next three trucks for 'Site 2') and as no balance trucks of 'Site 1', so 333 (three trucks for 'Site 3') now one balance truck for second site (total demand is 4 trucks) so 233 . The final dispatching sequence as per thumb rule will be: 11112223333233 .

Step 2: Go on changing the value of ' $\mathrm{C}$ ' from ' 12 ' to ' 6 ', till there is no change in the result shown by the model, for ' $\mathrm{TWT}=2: 25$ ', but at ' $\mathrm{C}=5$ ', the changes observed are 'TWT $=2: 30$ ' and 'TBB $=1: 10 \mathrm{pm}$ '.

Step 3: Now for ' $\mathrm{C}=5$ ' and keeping all other data same 'RUN' the model on GA, to get the required results.

To show effectiveness of the model same eight cases, that of earlier Table 18, were observed whose results for saving in trucks is listed below in Table 19.

Table 19 Summary of Result for different site situations from Single dispatching Plant

\begin{tabular}{|c|c|c|c|c|c|c|c|}
\hline $\begin{array}{l}\text { Case } \\
\text { No. }\end{array}$ & $\begin{array}{c}\text { No. of } \\
\text { Sites to } \\
\text { be } \\
\text { Delivered }\end{array}$ & $\begin{array}{c}\text { No. of } \\
\text { Total } \\
\text { Deliveries }\end{array}$ & $\begin{array}{c}\text { Type of } \\
\text { Plant } \\
\text { with } \\
\text { 'md' }\end{array}$ & $\begin{array}{c}\begin{array}{c}\text { No. of } \\
\text { Trucks } \\
\text { by } \\
\text { Thumb } \\
\text { Rule }\end{array}\end{array}$ & $\begin{array}{c}\text { No. of } \\
\text { Trucks by } \\
\text { MATLAB } \\
\text { App }\end{array}$ & $\begin{array}{c}\text { No. } \\
\text { RMC } \\
\text { trucks } \\
\text { saved }\end{array}$ & $\begin{array}{c}\% \\
\text { Saving } \\
\text { in No. } \\
\text { of } \\
\text { RMC } \\
\text { Trucks }\end{array}$ \\
\hline 2 & 3 & 12 & \multirow{4}{*}{$\begin{array}{c}\text { CP-30 } \\
20 \\
\text { minutes }\end{array}$} & 6 & 5 & 1 & 17 \\
\hline 4 & 2 & 12 & & 7 & 5 & 2 & 28 \\
\hline 6 & 5 & 18 & & 9 & 6 & 3 & 33 \\
\hline 8 & 2 & 18 & & 7 & 5 & 2 & 28 \\
\hline 1 & 3 & 12 & \multirow{4}{*}{$\begin{array}{c}\text { CP-90 } \\
3 \\
\text { minutes }\end{array}$} & 7 & 5 & 2 & 28 \\
\hline 3 & 2 & 12 & & 7 & 5 & 2 & 28 \\
\hline 5 & 5 & 18 & & 9 & 5 & 4 & 44 \\
\hline 7 & 2 & 18 & & 7 & 5 & 2 & 28 \\
\hline
\end{tabular}

\section{CONCLUSION:}

The present study demonstrates a successful application of GA model to suggest an un-interrupted dispatching schedule of RMC trucks. The result from Examples $1 \& 8$, shows that the interruptions of the sites were always reduced to zero, there by producing un-interrupted dispatching schedule. The present model also generate efficient, flexible and un-interrupted dispatching schedule. It helps plant manager to decide quickly the dispatching schedules which reduce waiting time, by $6 \%$ to $60 \%$, and reduces number of trucks required for dispatching an order by, $17 \%$ to $44 \%$, by providing flexibility (scope) to the dispatching manager for rescheduling the data parameters on a single window interface. 


\section{REFERENCES:}

1. Chung et. $\mathrm{Al}(2003)$ "Optimizing the Schedule of Dispatching RMC trucks through Genetic Algorithms", ELSEVIER, Automation in Construction 13 327-340.

2. Chung-Wei Feng, Hsien-Tang Wu (2004) "The Integrated RMC Dispatching system based on the Dispatching Center Approach", ASCE, Automation in Construction.

3. Ming Lu, Jijan-Ping Zhang (2004) "Concrete Plant Operations Optimization Using Combined Simulation and Genetic Algorithms", IEEE, 0-7803-8403-2/04.

4. Sakchi S. \& Thammasak R (2010) "Production Scheduling for Dispatching RMC Trucks Using Bee Colony Optimization", ISSN, 1941-7020.
5. Tarek M. Zayed, Daniel Halpin (2001) "Simulation of Concrete Batch Plant Production", ASCE, Construction \& Management, 127:132-141.

6. David Naso , Biagio Turchiano, Uzay Kaymak (2006) "Genetic algorithms for supply-chain scheduling: A case study in the distribution of ready-mixed concrete", ELSEVIER, Automation in Construction,177 (2007) (2069-2099) 2007.

7. Nuntana \& Wuthichai (2015), "Optimized Ready mixed concrete trucks schedule for uncertain factors using bee algorithm", Songklanakarin Journal of Science and Technology, 37(2), 221-230.

8. David E.Goldberg (2013), "Genetic Algorithms", PEARSON. 